\title{
Relativization strategies in Earlier African American Vernacular English
}

\author{
Gunnel Tottie and Michel Rey \\ University of Zurich
}

\section{ABSTRACT}

\begin{abstract}
This article, which examines the system of relative markers in Early African American English as documented in the Ex-Slave Recordings (Bailey et al., 1991), is intended as a contribution to two areas of research: African American Vernacular English and the system of relativization in English. We found a significantly higher incidence of zero marking in adverbial relatives than in non-adverbial relatives. Among non-adverbial relatives, a variable rule analysis showed that non-humanness of the head as well as the function of the head as subject complement or subject in an existential sentence strongly favored zero relatives, and that prepositional complement heads disfavored zeroes. The lack of wh-relatives as.well as the frequency of zero subject relatives is interpreted as evidence that African American Vernacular English is a dialect of English.
\end{abstract}

In this article, our aim is twofold: we wish to make a contribution to the study of relativization processes in English, and we wish to throw light on the relativization system in African American Vernacular English (AAVE), which has been given little serious attention in earlier work. Although there is by now a vast literature on both relativization processes in English and on AAVE, the intersection of the two sets of research is limited.

The system of relativization in English offers rich possibilities of synchronic variation between different forms, as in the man who/whom/that/ $\varnothing$ I love or the car that/which/ $\varnothing$ I bought. The factors governing the choice of different forms have been the object of many studies (e.g., Ball, 1996; Guy \& Bayley, 1995; Olofsson, 1981; Quirk, 1957; Tottie; 1995), but many parameters still remain to be elucidated, such as the influence of regional dialects, medium (speech vs. writing), register, literacy, and prescriptivism, as well as sociolinguistic factors (only social class seems to have been investigated so far; see Adamson, 1992). The use of zero relatives and the adverbial function of relative markers are two neglected problem areas to which we wish to give special attention in this study; we also devote some attention to the role of literacy in relative marker usage and discuss the influence of gender.

We are deeply grateful to Guy Bailey for giving us access to the tapes on which the Bailey et al. (1991) transcripts are based. We also thank Edgar Schneider and two anonymous reviewers for valuable comments and criticisms; the article has benefited greatly from their careful reading. We alone are responsible for any remaining inadvertencies. 
Similarly, although AAVE has attracted enormous attention from scholars in the past few decades and the question of its origin as a creole or a dialect of English has been hotly debated, most earlier studies of AAVE have paid little attention to relativization. ' We know of no monographs devoted entirely to relative constructions in AAVE; they have rarely been included among the grammatical features studied as characteristic of AAVE. The features that have been given attention have typically been multiple negation, verbal concord, deletion of the copula, invariant $b e$, and the intricate tense and aspect system of AAVE (for a recent overview, see Myhill, 1995).

Yet it seems to us that the system of relativization would be of great interest for the study of AAVE and its origins as a creole or a dialect of English; it is a less salient variable than the verbal features listed above, and the changes in the relativization system as well as its relation to other varieties of English vernaculars or creoles would be easy to overlook. In this article, we wish to make a contribution to the study of AAVE by describing and analyzing in some detail the relative constructions occurring in one particular sample of Early AAVE (or EAAVE): that is, the recordings of interviews with former slaves transcribed and published by Bailey, Maynor, and Cukor-Avila (1991).

We are not the first researchers to exploit these data from EAAVE. The audiotaped interviews published in Bailey et al. (1991), as well as a larger collection of transcribed interviews with former slaves published by Rawick (1972), have been used by Montgomery (1991) and Schneider (1989) for the study of relativization strategies. However, because of the goals of these authors (describing the use of relativization as part of the total linguistic.system of EAAVE [Schneider]; assessing the reliability of the EAAVE texts published in Rawick by comparison with the transcriptions of audiotapes given in Bailey et al. [Montgomery]), it was not part of the aim of either of these scholars to give a comprehensive survey of relative marker usage or the factors that condition it. Our aim is to show that a more comprehensive analysis can yield valuable new insights concerning both AAVE and relativization processes.

\section{EARLIER WORK ON RELATIVIZATION IN AAVE}

There are a few exceptions to the observation that previous writers on AAVE have paid little attention to the system of relativizers: Smith (1969), McKay (1969), Light (1969), Labov and Cohen (1973), and Martin and Wolfram (in press) all devoted some attention to relativization. Most of these studies, however, provide contradictory information. Based on interviews with African American speakers from Texas, Smith (1969) attempted to show the interdependence of left dislocation and zero subject relatives. The study focuses mostly on the occurrence of the obviously nonstandard items what and zero subjects (as in there's a man downstairs $\varnothing$ wants to talk to you), but it gives no overview of the system. In a similar vein, Dillard (1972:59) maintained 
that, if there is an overt relative marker in Black English, it is what. Labov and Cohen (1973:227) surprisingly asserted that which is the prevalent relative pronoun in AAVE and then gave an example containing only nonrestrictive relatives: John, which is seven, Linda which is six. We have not had access to Light (1969), who, according to Schneider (1989:218), claims that there are no subject zeroes in AAVE, but then contradicts himself by introducing at least one in an example.

Among these earlier writers, McKay (1969) provides the best survey of a system of relativization in AAVE, simply because she accounts for all the relatives found in her data, and not just those which deviate from standard English.-This study was based on the speech of a single elderly informant, comprising some 56 restrictive relative clauses. Her main concern was to give a generative-transformational account of the data, but it is possible to piece together a quantitative and functional picture from the information given. Interestingly, McKay found that zero is the most frequently used relativizer, used in $54 \%$ of all cases, and that more than half of those zeroes are subjects. That comes second with $38 \%$, and what accounts for $9 \%$; except for quotations from the Bible, who and which do not occur.

McKay's findings tally well with those studies we have found that are explicitly devoted to giving quantitative descriptive data concerning relativization strategies in AAVE. Both Schneider (1989) and Montgomery (1991) of fer valuable new insights into the use of relative markers in earlier AAVE, using overlapping sources. Schneider devoted a chapter to relative constructions in his comprehensive monograph on American Earlier Black English. His material-drawn from the Works Project Administration interviews with former slaves conducted in the 1930s and 1940s and later published in Rawick (1972)-did not exist in the form of audio recordings. Schneider's sample of relative pronouns was large, consisting of 786 relative clauses from 102 interviews.

Montgomery compared the transcriptions in Rawick, based on the written notes made by interviewers who were not professional linguists, with those published by Bailey et al. (1991), which were based on actual sound recordings and transcribed by linguists. His purpose was to assess the reliability of the Rawick material. He did this by taking a sample of 11 interviews each from Rawick and Bailey et al. and then comparing left dislocation and the use of relative pronouns in the two sets of data. He included Schneider's data for comparison with his own findings on relatives, in addition to comparing his findings with those of Mufwene's study of restrictive relativization in Gullah (1986). ${ }^{2}$ Montgomery found 167 relatives in his Rawick sample and 158 in the Ex-Slave Recordings. He subdivided them into restrictive and nonrestrictive relative clauses, but gave only pooled distributions of relative markers in his tables (1991:184). Table 1 gives an overview of Schneider's and Montgomery's findings.

In both Schneider's and Montgomery's material, the most frequent relative marker is zero ( $56 \%$ and $54 \%$ in Montgomery's Rawick and Ex-Slave 
TABLE 1. Relative markers in EAAVE (after Montgomery, 1991, Table 3, and Schneider, 1989:214, Table 19)

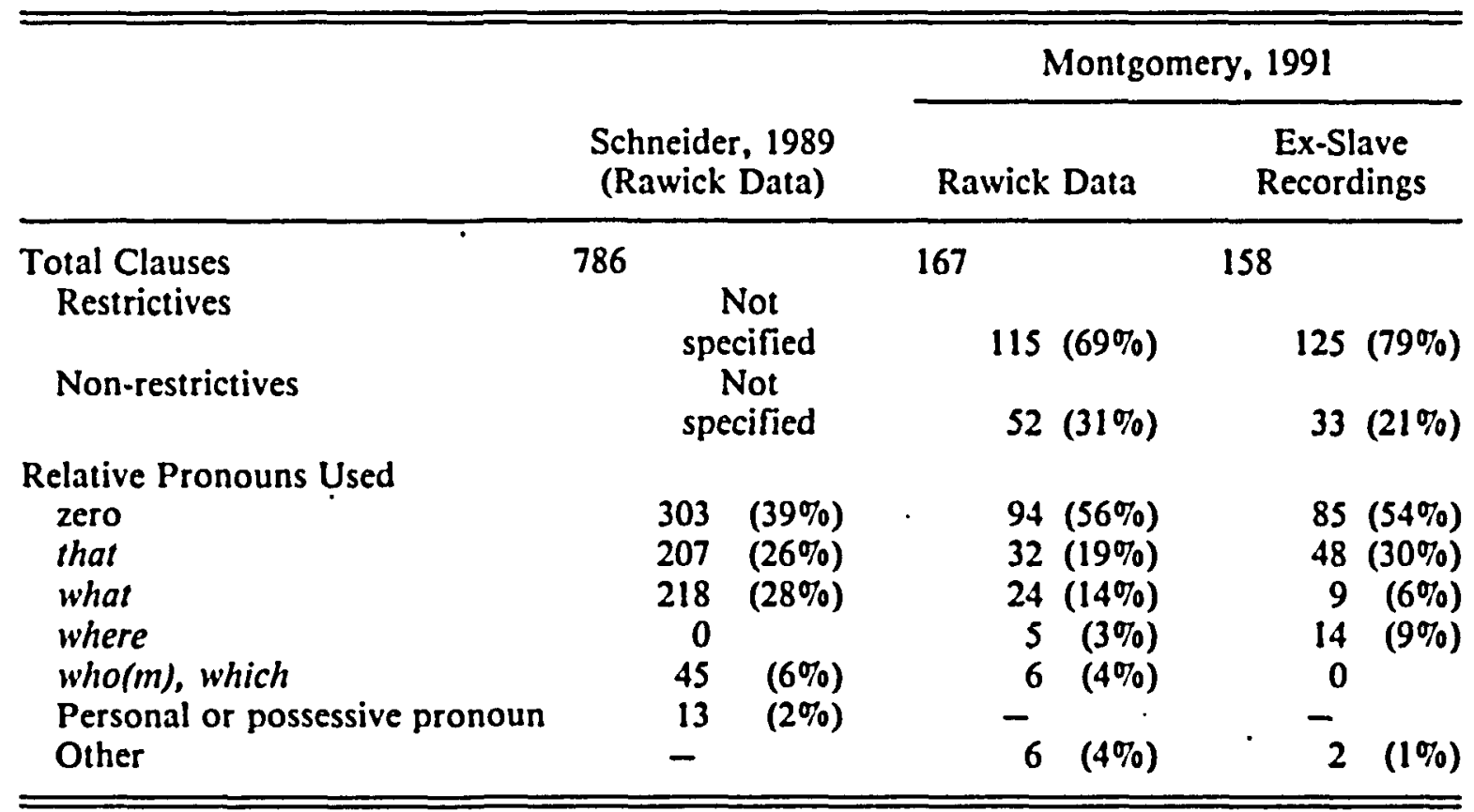

Recordings data, respectively, and $39 \%$ in Schneider's Rawick data), followed by that and what. That accounts for 19 to $30 \%$ in the different samples, whereas what is infrequent in the Ex-Slave Recordings with only $6 \%$ of the tokens, compared with $14 \%$ in Montgomery's Rawick sample and $28 \%$ in Schneider's mixed sample. Who and which are extremely infrequent in Rawick (4 to 6\%) and do not occur at all in the Ex-Slave Recordings. The high occurrence of what in Montgomery's Rawick sample was due to a single speaker, and, as Montgomery pointed out (1991:186), it could possibly have been introduced by the interviewer. Schneider also had a large proportion of what, produced by several speakers; again, it seems not impossible that some instances were introduced by interviewers as a salient feature of folk speech. As a relative marker, what is absent from standard varieties of English in both Britain and America, but occurs in many non-standard varieties. (See, e.g., Orton et al., 1978, for an overview of British dialects; Cheshire, 1982:72, for data from Reading teenage English; Wolfram \& Christian, 1976:121, for Appalachian English.) The lower incidence of zero relatives in Schneider's sample deserves comment and is better understood if the data are subdivided, as in Table 2.

In Table 2, the zero relatives are split up according to their syntactic function in the relative clause, and we see that in both Schneider's Rawick-based material and in Montgomery's Rawick sample the proportion of zero subjects is much lower than in the Ex-Slave Recordings: 6\% in Schneider's sample and $3 \%$ in Montgomery's, compared with $22 \%$ in the Ex-Slave Recordings. Zero subject relatives are extremely infrequent in contemporary standard English on either side of the Atlantic (see, e.g., Guy \& Bayley, 1995; Quirk et al., 
TABLE 2. The use of zero forms in relative clauses in EAAVE (after Schneider, 1989, and Montgomery, 1991)

\begin{tabular}{|c|c|c|c|c|c|c|c|c|c|}
\hline \multirow{3}{*}{$\begin{array}{l}\text { Function in } \\
\text { Relative Clause } \\
\text { Non-subject }\end{array}$} & \multicolumn{3}{|c|}{$\cdot$} & \multicolumn{6}{|c|}{ Montgomery, 1991} \\
\hline & \multicolumn{3}{|c|}{$\begin{array}{l}\text { Schneider, } 1989 \\
\text { (Rawick Data) }\end{array}$} & \multicolumn{3}{|c|}{ Rawick Data } & \multicolumn{3}{|c|}{$\begin{array}{l}\text { Ex-Slave } \\
\text { Recordings }\end{array}$} \\
\hline & & 286 & $(94 \%)$ & & 91 & $(97 \%)$ & & 66 & $(78 \%)$ \\
\hline $\begin{array}{l}\text { Human head } \\
\text { Non-human head }\end{array}$ & $\begin{array}{r}40 \\
246\end{array}$ & & & $\begin{array}{r}3 \\
88\end{array}$ & & & $\begin{array}{r}7 \\
59\end{array}$ & & \\
\hline Subject & & 17 & $(6 \%)$ & & 3 & $(3 \%)$ & & 19 & $(22 \%)$ \\
\hline $\begin{array}{l}\text { Human head } \\
\text { Non-human head }\end{array}$ & $\begin{array}{r}15 \\
2\end{array}$ & & & $\begin{array}{l}2 \\
1\end{array}$ & & & $\begin{array}{r}19 \\
0\end{array}$ & & \\
\hline Total & & 303 & & & 94 & & 85 & & \\
\hline
\end{tabular}

1985), and Montgomery therefore surmised that the Rawick material was probably edited on this point by the interviewers, who were obviously.literate speakers of more standard varieties of English. Because both left dislocation, the other variable examined by Montgomery, and relative pronouns pattern in more non-standard ways in the Ex-Slave Recordings than in Rawick, he concluded that the Rawick narratives had "undergone unconscious standardization with regard to these features" (1991:188).

Schneider and Montgomery also drew conclusions bearing on the debate concerning the origins of AAVE as a creole or a dialect of English. Contra Dillard (1972), both came to the conclusion that the language of the former slaves was similar to other vernaculars spoken in the American South. Montgomery compared his findings and those reported by Mufwene (1986) on restrictive relativization in Gullah. He noted the absence of that in Gullah and of the creole relatives weh and wa in the Ex-Slave Recordings and Rawick and concluded: "[The data] collected in the WPA materials, however ... reveals little resemblance between the speech of the elderly ex-slaves interviewed and Gullah; if anything, the WPA material suggests that the black speech it contains showed greater similarity to Southern white folk speech" (1991:187). Schneider made large-scale comparisons with other non-standard varieties of English, concluding that "the parallels between the relative pronouns of E[arlier] B[lack] E[nglish] and those of earlier stages of English and English dialects, to some extent also including quantitative relationships, provide convincing evidence of this descent" (1989:220).

RELATIVIZATION IN THE EX-SLAVE NARRATIVES

ON AUDIOTAPE

There are many problems not addressed by Schneider and Montgomery. Both carefully separate out subject and non-subject zero relatives, but neither of 
them breaks down the material in this way with the other relative markers. Schneider accounted for the humanness of the antecedent head nouns for all types of relative pronouns, but Montgomery did this only for zeroes. This means that, based on their accounts, we cannot answer such questions as the following: What proportion of all subject relatives are zeroes? What proportion of all object relatives are zeroes? How are other relative markers used? When are that or what preferred to zero?

Furthermore, neither Schneider nor Montgomery takes adverbial relatives into account, and as we shall see, these represent a very substantial proportion of all cases, with interesting properties of their own. ${ }^{3}$ Schneider left them out of his investigation altogether and did not list the adverbial relatives when, where, why among the possible relatives, referring only to relative pronouns (1989:213). Montgomery was less explicit: he did not mention relative adverbs, but did include several instances of where (see Table 1). Moreover, neither Schneider nor Montgomery differentiates between restrictive and non-restrictive relative clauses when they account for the different pronouns; however, this is not a very crucial omission because of the paucity of non-restrictives in the material.

What we propose to do is to take a closer look at all headed relative constructions with finite relative clauses in the audiotaped Ex-Slave Narratives, excluding non-headed constructions like What you say is true, Whatever you do is wrong, in the same way as Schneider and Montgomery did. In order to permit comparisons with other varieties of English, we examine the following groups of factors that have been shown by Quirk (1957), Olofsson (1981), Guy and Bailey (1995), and Tottie (1995) to be of importance for the choice of relative markers in other varieties of English:

1. the grammatical category of the antecedent NP head: e.g., noun in the dog that I bought or pronoun in anything $\varnothing$ you say;

2. premodification or not of the NP head, as in the red coat $\varnothing$ I saw or the coat $\varnothing$ I saw;

3. humanness/non-humanness of the NP head, as in the boy/book that you saw;

4. syntactic function of the NP head in the matrix clause: e.g., subject in The person who recommended it was my teacher or direct object in I saw the book that you recommended;

5. adjacency/non-adjacency of the NP head and the relative marker, as in The day when he left was a Thursday versus The day at the beginning of January when he left was a Thursday;

6. syntactic function of the relative marker in the relative clause: e.g., subject in The person who recommended it was my teacher or direct object in I saw the book that you recommended;

7. category membership of the subject of the relative clause: e.g., personal pronoun in I bought the book that you recommended, noun in I bought the book that my teacher recommended, or relative marker in I bought the book that was at the top of the best-seller list. 
The following factors are also discussed: relative markers as prepositional complements, as in the man that I spoke to; resumptive relative pronouns, as in the man that I saw him; and the gender of the speaker.

We explicitly treat relative markers in adverbial function, including where, when, and why, as in principle they exhibit the same variation with zero and that as the non-adverbial relatives do; we give a separate account of their use. The terms "relative marker" or "relativizer" are used throughout to emphasize the fact that not only pronominal relatives are included. When referring to the entire NP construction comprising the head (premodified or not) and relative clause, we use the term "relative complex."

We give a quantitative survey of our results and also, in the case of nonadverbial relatives, endeavor to disentangle the factors possibly influencing the choice of relative markers to establish their independent effects by a variable rule analysis using GOLDVARB 2 (see Rand \& Sankoff, 1990).

We compare AAVE with several other dialects of English. We argue that the explanation for some of the phenomena, especially the high incidence of that and subject zeroes (and the concomitant absence of forms of who and which) lies in the fact that this is the language of people who have had little exposure to literacy. We relate our study of relative markers to the study of the discourse strategies employed in spoken English, especially the relativization strategies discussed by Fox (1987) and Fox and Thompson (1990), and we support our discussion with data on relative clauses from studies of other regional and chronological varieties of English.

Our conclusion concerning the creole/dialect issue does not differ from that of Schneider or Montgomery: we agree that the relative constructions in the EAAVE sample strongly support its status as a dialect of English and not a creole. However, bearing the caveats of Rickford (1991) in mind, we do not wish to argue that our sample is an example of a deep vernacular form of EAAVE; we do not see it as representative of earlier centuries of AAVE, nor do we even claim that it is representative of the EAAVE of the mid-19th century, as the sample is restricted in terms of numbers of speakers and the regions they come from (four from Texas, four from Alabama, and one each from Georgia, Virginia, and Louisiana). Furthermore, at least in the case of relative markers, there is an additional cause for concern, in that the individual speakers contribute very different proportions of relative constructions. However, the Ex-Slave Recordings constitute the only available corpus of spoken EAAVE, and as such it has intrinsic value for the historical study of AAVE. ${ }^{4}$ We regard it as a mesolectal variety (to the extent that it is homogeneous enough to be called a variety) of the English spoken by Black speakers in the American South in the last century, which can be subjected to interesting comparisons with other varieties of English. Lastly, this material is of particular interest from the point of view of studying the spoken/written dichotomy: although some, if not all, of the speakers were literate (one of them, Uncle Bob Ledbetter, explicitly stated that he could read and write: I could read and write too ... Course I can't write it pretty like people do 
do ... ; Bailey et al., 1991:49), it is unlikely that they had much exposure to written English. We are thus dealing with a variety of spoken English which has not been much influenced by written varieties.

\section{METHOD}

First we searched the printed texts of the Ex-Slave Narratives in Bailey et al. (1991) for relative constructions, and then we listened to all the tapes to check the examples. ${ }^{5}$ We found the transcriptions very accurate as far as relative markers were concerned, and in most cases we accepted the transcriptions in the printed version. ${ }^{6}$

Our total sample amounted to 164 restrictive relative clauses, including 48 adverbial relatives, plus 7 non-restrictive relative clauses, giving a total of $171 .^{7}$ This includes one example which we counted twice because of hesitation and repetition with another relative marker (see (20)).

It can sometimes be problematic to separate out non-restrictive from restrictive relative clauses, but it is definitely less so when one has access to audiotapes. As pointed out by Quirk (1957:101), non-restrictive clauses are characterized by "a fresh intonation contour, and a change (especially a diminution) in the degree of loudness." We relied on Quirk's intonational criteria when meaning was an insufficient criterion.

The proportion of non-restrictives is low as in all vernaculars (cf., e.g., Cheshire, 1982; Macaulay, 1991). Three of them are adverbial relatives with where, but some speakers use the markers that or what. Sentences (1) through (4) exemplify the different types; notice that the repeated relative that in (2), followed by resumptive he, also has a temporal function, and that there is even a non-restrictive relative clause with zero relative in (4). (References after examples give the initials of the speaker and the line number of the entry; full names are given in Table 4.)

(1) An' D.J., when they bringing me from Africa, Liberia Africa, where I was was brought from. CS 23

(2) But see see she'd nurse this baby that, that he would be hungry. LS 131

(3) We killed bears an' panthers an' things like that, what was eating up the stock. CS 142

(4) [A]n' he was gonna whip my, my mother's boy $\varnothing$ pack water. LS 232

The bulk of the relatives in the Ex-Slave Recordings thus consists of restrictive relative clauses. ${ }^{8}$ Henceforth we will report on only these. The overall distribution of relative markers in restrictive relative clauses is shown in Table 3. Table 3 of fers no surprises, as the main characteristics of the relatives used in this material were already known from Montgomery (1991) (sèe Table 1). As Montgomery pointed out, the absence of who, whom, whose, and which is noteworthy. Notice that the absence of these forms also means that piedpiping cannot occur. There are no forms like The man to whom I spoke or 
TABLE 3. Relative markers in restrictive relative clauses in the Ex-Slave Recordings

\begin{tabular}{ccccccc}
\hline Zero & That & What & Where & When & Why & Total \\
\hline 102 & 39 & 11 & 10 & 1 & 1 & 164 \\
$62 \%$ & $24 \%$ & $7 \%$ & $6 \%$ & $1 \%$ & $1 \%$ & \\
\hline \hline
\end{tabular}

TABLE 4. Individual speaker contributions to the sample of EAAVE relative constructions

\begin{tabular}{lccccccccccc}
\hline \hline Speaker & Zero & That & What & Where & When & Why & Total & $\%$ & Pages & $\begin{array}{c}\text { Relatives/ } \\
\text { Page }\end{array}$ \\
\hline Wallace Quarterman & 1 & 0 & 0 & 0 & 0 & 0 & 1 & $1 \%$ & 5 & 0.2 \\
Isom Moseley & 0 & 1 & 0 & 0 & 0 & 0 & 1 & $1 \%$ & 4 & 0.3 \\
Alice Gaston & 0 & 3 & 0 & 1 & 0 & 0 & 4 & $2 \%$ & 1 & 4 \\
Celia Black & 5 & 1 & 0 & 0 & 0 & 0 & 6 & $4 \%$ & 1 & 6 \\
Bob Ledbetter & 10 & 1 & 1 & 0 & 0 & 0 & 12 & $7 \%$ & 6 & 2 \\
Fountain Hughes & 5 & 9 & 0 & 0 & 0 & 1 & 15 & $9 \%$ & 12 & 1.3 \\
Billy McCrea & 11 & 2 & 1 & 1 & 0 & 0 & 15 & $9 \%$ & 4 & 3.8 \\
Harriet Smith & 10 & 8 & 0 & 4 & 1 & 0 & 23 & $14 \%$ & 19 & 1.2 \\
Laura Smalley & 19 & 5 & 5 & 3 & 0 & 0 & 32 & $20 \%$ & 15 & 2.1 \\
Charlie Smith & 41 & 9 & 4 & 1 & 0 & 0 & 55 & $33 \%$ & 12 & 4.6 \\
Total & 102 & 39 & 11 & 10 & 1 & 1 & 164 & & & \\
& $62 \%$ & $24 \%$ & $7 \%$ & $6 \%$ & $1 \%$ & $1 \%$ & & & & \\
\hline \hline
\end{tabular}

The state in which I was born, but, as we shall see, stranded prepositions are not infrequent. There is one instance each of when and why as relative markers, which were not explicitly shown by Montgomery; however, they could have been subsumed under "Other" in his data.

Table 4 shows the contributions of the individual speakers to the relatives sample. Table 4 demonstrates very clearly that the sample is highly skewed. The first four speakers in the table contribute a total of only $8 \%$ of the relative constructions, the next three account for another $25 \%$, and the last three contribute $67 \%$. Notice also that, among these speakers, a single individual, Charlie Smith, makes the largest contribution to the whole sample (33\% of the total). ${ }^{9} \mathrm{He}$ is also the speaker with probably the highest exposure to the English spoken by Whites, as he was brought up by a white family as one of their own children and then spent most of his life as a cowboy. This was not an entirely unusual career for a Black man, ${ }^{10}$ but Charlie Smith himself seems to have had no Black fellow-workers; as he himself stated: I was the onlies' colored cowboy (Bailey et al., 1991:110). However, the distribution of the various relative markers in Charlie Smith's speech does not seem much different from that of the other speakers. 
TABLE S. Relative markers in the main and adverbial samples

\begin{tabular}{llllllll}
\hline \hline Sample & Zero & That & What & Where & When & Why & Total \\
\hline Main sample & 68 & 38 & 10 & 0 & 0 & 0 & 116 \\
Adverbial sample & $59 \%$ & $34 \%$ & $9 \%$ & $0 \%$ & $0 \%$ & $0 \%$ & \\
& 34 & 1 & 1 & 10 & 1 & 1 & 48 \\
& $71 \%$ & $2 \%$ & $2 \%$ & $21 \%$ & $2 \%$ & $2 \%$ & \\
\hline \hline
\end{tabular}

The fact that the contributions are of such different magnitudes can be related to two factors: the length of the individual interviews and the density of occurrence of relative constructions in the grammars of individual speakers. The length of the individual contributions can be roughly estimated in terms of the number of transcribed pages, as we have done in the column headed "Pages" in Table 4. It is natural that the contribution of speaker 3 , Alice Gaston, which covers only one page of transcription, should be smaller than those covering twelve to nineteen times as many pages, but notice that speaker 6, Fountain Hughes, has only 15 relative constructions in twelve pages, whereas speaker 7, Billy McCrea, needs only four pages to produce the same number of relative constructions, and speaker 10, Charlie Smith, produces as many as 55 relative constructions in his twelve pages. With the usual caveats concerning sample size, we give the individual frequencies of relative constructions, calculated as the number of relative constructions per page, in the rightmost column of Table 4 . How the frequency of relativization is related to the grammars of individuals or possibly to discourse factors such as levels of formality or information flow must remain an open question at present; it remains an interesting matter for scholars to pursue.

We subdivided the corpus into an adverbial sample, where the relative markers where, when, why, zero, or others have an adverbial function in the relative clause (as in The house where I live is white), and a main dataset, henceforth the main sample, consisting of all relative constructions without a relative marker in adverbial function. As pointed out by Macaulay (1991), who did not include adverbial relatives in his survey of vernacular Scottish English, there are two reasons for separating out adverbial relatives: they tend to be formulaic, and they do not always have complete variability of forms.

Table 5 shows the distribution of relative markers in the main and adverbial samples. Although zero is the majority marker in both samples, there are differences in the proportions of zero in the two samples. In the adverbial sample ( $n=48$, or $29 \%$ of the total number), the frequency is as high as $71 \%$, with only $29 \%$ relative markers (mostly where, with one instance each of when, why, that, and what). In the main sample, the proportion of zero relatives is lower $(59 \%$ of the tokens, or $68 / 116)$, but it still comes out at the top. The second most common marker is that $(34 \%$ or $38 / 116)$. What accounts for a mere $9 \%(10 / 116)$ of the tokens. The difference in proportion 
of zero relatives versus non-zeroes in the two samples is not statistically significant ( $p>.1$, chi-square $2.154,1 d f$ ); however, if we test for that versus non-that, the difference is highly significant $(p<.001$, chi-square $17.626,1 d f)$.

As it has sometimes been contended that relative markers occurring in cleft constructions (as in It was John who did it) are not true relatives (see Ball, 1994, for discussion), it is worth adding that there were no instances of itcleft sentences in the main sample, and only one in the adverbial sample. There were five instances of resumptive pronouns: see (2), (47), and (48).

\section{ADVERBIAL RELATIVES}

First we present and discuss the characteristics of the adverbial relatives, which account for $29 \%(48 / 164)$ of all examples and are the least studied type of relative constructions. They have been treated variously by different authors, either included without much comment (e.g., Romaine, 1982), partially included (Quirk, 1957, included prepositional relatives, but not constructions with where, when or why), or completely excluded because of their peculiarities (constraints on antecedents and relative markers) (e.g., Macaulay, 1991). Few writers have devoted special attention to them; notable exceptions include Guy and Bayley (1995) and, among the historical accounts, Jespersen (1927) and Fischer (1992).

The best account of adverbial relatives we have found is given in Quirk et al. (1985:1252-1257), which is both systematic and exhaustive. The authors provide a fairly detailed account of usage in standard English, showing that there can be as many as seven possibilities of relativizing on adverbial positions, " but that "there are considerable and complicated restrictions on [the] $w h$-forms which operate in relative clauses expressing place, time, and cause" (1985:1254). Furthermore, as they pointed out, "there is no relative how parallel to where, when, why to express manner with an antecedent noun"; the acceptability of that varies from one construction to another (Quirk et al. 1985:1254, 1256).

Following Quirk et al., we distinguish four semantic types of adverbial relative clauses, expressing the notions of time, cause, manner, and place, respectively. Table 6 displays the realizations of adverbial relative markers in the Ex-Slave Recordings. Although the present material is small $(n=48)$, it is revealing to study it in detail. We have already seen in Table 3 that, among the adverbial relatives, $71 \%$ have zero realization. Table 6 shows that the largest semantic category is that of locative adverbials; with 20 instances, they account for $42 \%$ of the total. Time and manner adverbial relatives account for $23 \%$ each, and adverbial relatives expressing cause are the smallest category, accounting for $13 \%$ ( 6 instances). Table 6 also shows that, in three out of the four semantic categories, there is not much actual variation in the realization of relative adverbials. Among the time adverbials, there are 
TABLE 6. Relative markers in the EAAVE adverbials sample

\begin{tabular}{lclllllll}
\hline \hline Adverbial Type & Zero & What & That & Where & When & Why & Total & $\%$ \\
\hline Place & 9 & 1 & 0 & 10 & 0 & 0 & 20 & $42 \%$ \\
Time & $45 \%$ & $5 \%$ & $0 \%$ & $50 \%$ & $0 \%$ & $0 \%$ & & \\
& 9 & 0 & 1 & 0 & 1 & 0 & 11 & $23 \%$ \\
Manner & $82 \%$ & $0 \%$ & $9 \%$ & $0 \%$ & $9 \%$ & $0 \%$ & 11 & $23 \%$ \\
Cause & 11 & 0 & 0 & 0 & 0 & 0 & 11 & \\
& $100 \%$ & $0 \%$ & $0 \%$ & $0 \%$ & $0 \%$ & $0 \%$ & & $13 \%$ \\
Total & 5 & 0 & 0 & 0 & 0 & 1 & 6 & $13 \%$ \\
& $83 \%$ & $0 \%$ & $0 \%$ & $0 \%$ & $0 \%$ & $17 \%$ & & \\
& 34 & 1 & 1 & 10 & 1 & 1 & 48 & \\
\hline \hline
\end{tabular}

two non-zero realizations, and among the cause adverbials, there is a single non-zero; in the category of manner, there are only zeroes.

The locative adverbials present the most varied picture. Only $50 \%(9 / 18)$ of them have a zero relativizer; eight have where, and there is a single instance of what. It seems possible to distinguish a few patterns even in this very limited material. Thus, there are five instances where the antecedent is either everywhere or anywhere; all of them have a zero relativizer, as in (5) and (6).

(5) Why then we'd jus' go an' stay anywhere $\varnothing$ we could. FH 117

(6) Everywhere $\varnothing$ you hears me you hear me singing a song, a reel. BL 32

Place(s) occurs four times, once with zero and three times with where, and room occurs once with where.

(7) Going off [to] the places where they's free. LS 412

(8) No, they didn' know nothing, you know, only read the Bible sometimes in places $\varnothing$ they could read a little. HS 367

What is of interest to us is that less generic words denoting place, such as town, colony, and spot, occur every time not only with where, but also with a stranded preposition. State occurs (five times in the speech of the same informant) variably with zero and where, but always with a stranded preposition. (Possibly the use of where in (10) should be related to the fact that there is intervening material between the antecedent and the relative marker.) The locatives are also the only relatives governed by a preposition in this material, occurring even after where. Sentences (9) through (12) all have stranding.

(9) Right, right in town where we living at. BM 53

(10) I could go right to the spot now nearly where he was killed at. HS 418 
(11) He went, went back in the state $\varnothing$ he was, he was born an' raised in. CS 285

(12) An' Guiteau killed him an' went back in that state what he was born an' raised in. CS 292

In addition to the restrictions on adverbial relative markers, Quirk et al. also pointed out that there are restrictions on the antecedent nouns. All the examples of manner adverbial relatives in the Ex-Slave Recordings had the same antecedent, way, and zero relative markers. Sentences (13) through (15) are typical of the formulaic character of this type.

(13) An' they say tha's the way $\varnothing$ they use' to do in slavery time. LS 382

(14) So tha's the way $\varnothing$ I carried myself. CB 26

(15) Tha's the way $\varnothing$ we learned. BL 176

The constructions with reason/cause relative adverbials are similarly formulaic: the antecedent is always reason, "virtually the only possible antecedent" according to Quirk et al. (1985:1255). In our sample, all the examples had the antecedent reason. There was only one instance of reason why, a disfavored variant according to Quirk et al. (1985:1253).

(16) An' that's the reason why I don't like to talk about it. FH 258

(17) If you be do the wrong thing, an' they sen' me after you, only reason $\varnothing$ I won' get you, I won't see you. CS 233

The time adverbials are similarly limited, both as regards their antecedents and their realizations. As Quirk et al. pointed out (1985:1255), "the most generic nouns ... seem to be preferred." In our material, nine out of eleven examples have time(s) as the antecedent, and one has day:

(18) But I, I 'member, you know, the time $\varnothing$ they give them a big dinner, you know, on the nineteenth. LS 440

(19) You, yeah, I recollect jus' as well, day $\varnothing$ they come roun' ... BM 17

The one instance of when appears to have been introduced as the result of hesitation in (20):

(20) I know of times $\varnothing$ they, when, when they mistreated people... HS 118

The instances of the frequent antecedent nouns without a following relative marker seem to border on grammaticalization. Thus, the lexical items (the) way, day, and time appear to serve grammatical functions; notice the parallelism between (19) I recollect ... day $\varnothing$ they come roun' and the constructed variant $I$ recollect... when they come roun' and (18) I 'member... the time $\varnothing$ they give them a big dinner and the constructed variant I'member ... when they give them a big dinner. Compare also the manner 
and cause adverbials in the way we learned, the reason I won't get you. We obviously have a gradient between headed and non-headed relative constructions here. The heads way and reason could just as well be classified as relative adverbs on a par with how and why.

It is interesting but also problematic to compare these results with those given by Guy and Bayley (1995) for their corpus of present-day spoken and written American English: they do not specify the probabilities for speech and writing separately, nor are the proportions of pied-piping compared with other forms. Guy and Bayley reported only 69 instances of adverbial relatives (just over $8 \%$ ) in their corpus of 827 restrictive relative clauses, drawn from educated speech and academic writing (roughly $75 \%$ speech). Strangely, no adverbials of reason and cause were found. They included the adverbial relatives in their VARBRUL analysis, and for locatives, the largest category in their material, they reported a strong probability for $w / h$, presumably including pied-piping forms with which and where $(p=.95)$. For manner adverbials, zero is preferred $(p=.99)$. Both zero and wh-forms were selected for time adverbials (based on a sample of only nine instances), with probabilities of .67 and .69 , respectively. These results show certain similarities to our findings for the Ex-Slave Recordings, but because of the restrictions in the reporting of Guy and Bayley, they must be interpreted with caution.

In summary, we see great similarities between the Ex-Slave Recordings and standard English, even British standard English as described by Quirk et al. (1985), in the restricted and formulaic uses of adverbial relative constructions. It is very probable that these types of examples were formulaic collecations even in earlier periods of Modern English. There is evidence for this in the castigation of the constructions without a relative marker (e.g., Swift's in the posture I lay) by early grammarians such as Lowth and Lindley Murray, as quoted by Quirk (1957:104, fn.) In our opinion, this very similarity to Early Modern English gives powerful support to the view that the EAAVE represented by the Ex-Slave Recordings is a dialect of English and not a creole.

NON-ADVERBIAL RELATIVES

Next, taking a closer look at the main sample of non-adverbial relative constructions, we try to establish some of the factors influencing the choice among the different relative markers. We begin by examining main clause factors pertaining to the antecedent head; then we examine relative clause factors and one sociolinguistic factor, gender. We also comment on the choice of relative marker with stranded prepositions and resumptive pronouns.

A variable rule analysis using GolDVARB is included to determine the individual effects of the factors.

\section{Main clause factors}

The characteristics of the NP head were of three kinds: (1) formal (its category membership; whether it was premodified; and adjacency (i.e. whether 
TABLE 7. Category membership of antecedent heads

\begin{tabular}{llcccc}
\hline \hline & Zero & That & What & Total & $\%$ \\
\hline Definite NP & 34 & 24 & 4 & 62 & $53 \%$ \\
Indefinite NP & $55 \%$ & $39 \%$ & $6 \%$ & & \\
& 17 & 7 & 2 & 26 & $22 \%$ \\
Pronoun & $65 \%$ & $27 \%$ & $8 \%$ & & \\
& 17 & 6 & 4 & 27 & $23 \%$ \\
Numeral & $63 \%$ & $22 \%$ & $15 \%$ & & \\
& 0 & 1 & 0 & 1 & $1 \%$ \\
Total & $0 \%$ & $100 \%$ & $0 \%$ & & \\
& 68 & 38 & 10 & 116 & \\
& $59 \%$ & $33 \%$ & $9 \%$ & & \\
\hline \hline
\end{tabular}

it was postmodified or otherwise separated by some linguistic material from the beginning of the relative clause); (2) semantic (whether the referent of the head noun was human or non-human), ${ }^{12}$ and (3) functional (the function of the head noun in the matrix clause).

If we look first at the category membership of the NP head we see from Table 7 that most antecedent heads are definite NPs, just as in the other corpora of relative constructions in English. Definite NP heads have frequently been thought to be a factor favoring zero relativization, but this could not be substantiated by the variable rule analysis carried out by Tottie (1995; see the literature review in that work). In the Ex-Slave Recordings, zero relative marker is in fact chosen more frequently when the NP head is an indefinite NP $(65 \%$ of all cases) or a pronoun $(63 \%)$. The instances with pronominal heads deserve some comment. There were eighteen relatives in non-subject function following pronominal heads; of these, fifteen consisted of or incorporated universal quantifiers (all, every, any), including seven instances of everything and five of all. Only in one case was there a surface relative marker; see (21). Otherwise zero prevailed exclusively, as in (22) through (25).

(21) All that I knowed they teach you is mind your master an' your mistress. HS 111

(22) He said millionaires dies an' leave all $\varnothing$ they got. CS 127

(23) An' tha's all $\varnothing$ I can go by. BL 13

(24) Don' want everything $\varnothing$ somebody else has got. FH 12

(25) So, they, you know, they could get everything $\varnothing$ they had if they didn' work. LS 492

Interestingly, this usage is very similar to what Ryden (1966:Table XII) found for highly literate 16th-century English. It also tallies well with Olofsson (1981:94ff.): in a sample of relative constructions from the Brown Corpus of edited 20th-century American English, antecedent heads containing so-called special modifiers (i.e., "superlatives [including the only] and some indefinite pronouns, notably all, any, every, no") co-occurred with zero 
TABLE 8. Premodification of NP head

\begin{tabular}{lllccc}
\hline \hline & Zero & That & What & Total & $\%$ \\
\hline Non-premodifiable & 13 & 6 & 3 & 22 & $19 \%$ \\
Not premodified & $59 \%$ & $27 \%$ & $14 \%$ & & \\
Premodified & 30 & 22 & 4 & 56 & $48 \%$ \\
& $54 \%$ & $39 \%$ & $7 \%$ & & \\
Total & 25 & 10 & 3 & 38 & $33 \%$ \\
& $66 \%$ & $26 \%$ & $8 \%$ & & \\
& 68 & 38 & 10 & 116 & \\
\hline \hline
\end{tabular}

relativizer in non-subject function in over $80 \%$ of all recorded cases. Olofsson also included compound indefinite pronouns in this category.

The use of zero after special modifiers should also be related to premodification of the NP head in general. However, we must bear in mind that not all antecedent heads are capable of modification; thus, pronouns such as anybody or everything cannot take premodifiers or determiners (*this everything, *the great everything). NP heads must therefore be subdivided into premodifiable and non-premodifiable heads to avoid skewing the results. If we do that, we see in Table 8 that premodification tends to coincide with a preference for zero: $66 \%$ of the premodified heads were followed by zero relatives, compared with $54 \%$ of the non-premodified antecedent heads. Nonpremodifiable heads, on the other hand, had a somewhat higher proportion of zeroes $(59 \%)$ than the premodified heads, possibly because they already incorporated some kind of special modification in Olofsson's terminology (i.e., they contained an instance of any or every). For examples of unpremodifiable heads, see sentences (21) through (25). Sentences (26) through (29) are examples of non-premodified heads followed by that and premodified heads followed by zero.

(26) Mr. P, he was one of the preachers that lived across from us. HS 92

(27) The man that raise me name me Charlie Smith. CS 10

(28) [A]n' if i's the las' word $\varnothing$ I've got to tell you, I never even much as tried to buy a, a shirt on time. FH 75

(29) Them N.'s would work for the meanes' people $\varnothing$ there was [Su-] 'round. BL 103

Superlatives have frequently been singled out in the literature (see, e.g., Olofsson, 1981) as having a tendency to collocate with zero relatives. We separated out the superlatives among the premodified NP heads in our material. As can be seen from Table 9, they do have a higher frequency of zero relatives $(\mathbf{7 4 \%})$, compared with $54 \%$ and $58 \%$ for non-premodified heads or 
TABLE 9. Superlative preceding NP head (premodifiables only)

\begin{tabular}{llllll}
\hline & Zero & That & What & Total & $\%$ \\
\hline Not premodified & 30 & 22 & 4 & 56 & $60 \%$ \\
& $54 \%$ & $39 \%$ & $7 \%$ & & \\
-Superlative & 11 & 6 & 2 & 19 & $20 \%$ \\
& $58 \%$ & $32 \%$ & $11 \%$ & & \\
+Superlative & 14 & 4 & 1 & 19 & $20 \%$ \\
& $74 \%$ & $21 \%$ & $5 \%$ & & \\
Total & 55 & 32 & 7 & 94 & \\
& $59 \%$ & $34 \%$ & $7 \%$ & & \\
\hline
\end{tabular}

TABLE 10. Special modifiers preceding NP head in premodified structures

\begin{tabular}{lccccc}
\hline & Zero & That & What & Total & $\%$ \\
\hline Special modifier & 16 & 6 & 1 & 23 & $61 \%$ \\
Other & $70 \%$ & $26 \%$ & $4 \%$ & & \\
& 9 & 4 & 2 & 15 & $39 \%$ \\
Total & $60 \%$ & $27 \%$ & $13 \%$ & & \\
& 25 & 10 & 3 & 38 & \\
& $66 \%$ & $26 \%$ & $8 \%$ & & \\
\hline
\end{tabular}

heads with non-superlative premodifiers, respectively. However, if we add special modifiers in Olofsson's sense (i.e., instances with any, every, or no), the proportion of zeroes does not increase in our corpus, but goes down to $70 \%$ (see Table 10). But the material is too small to warrant a discussion here.

Adjacency of the NP head and the relative marker has been shown to coincide with the choice of zero in both standard British English and standard American English by Quirk (1957) and Olofsson (1981); it was also shown to be an independent factor strongly favoring zero relativization by Guy and Bayley (1995). The distribution of relative markers over adjacent and nonadjacent constructions in our material is shown in Table 11 . We see that, when the relative marker is not adjacent to its antecedent NP head, the frequency of zero relatives is much lower than otherwise (only 19\%), compared with when there is no intervening material $(65 \%)$. Sentences (30) and (31) are typical examples of non-adjacent heads and relativizers. Compare also (10) with an adverbial relative with intervening material. Intervening material is set off with slashes in the examples. 
TABLE 11. Adjacency of NP head and relative marker

\begin{tabular}{llllll}
\hline & Zero & That & What & Total & $\%$ \\
\hline Adjacent & 65 & 29 & 6 & 100 & $86 \%$ \\
Not adjacent & $65 \%$ & $29 \%$ & $6 \%$ & & \\
& 3 & 9 & 4 & 16 & $14 \%$ \\
Total & $19 \%$ & $56 \%$ & $25 \%$ & & \\
& 68 & 38 & 10 & 116 & \\
& $59 \%$ & $33 \%$ & $9 \%$ & & \\
\hline \hline
\end{tabular}

TABLE 12. Humanness of referent

\begin{tabular}{llllll}
\hline & Zero & That & What & Total & $\%$ \\
\hline Human & 34 & 32 & 7 & 73 & $63 \%$ \\
Non-human & $47 \%$ & $44 \%$ & $10 \%$ & & \\
& 34 & 6 & 3 & 37 & $37 \%$ \\
Total & $79 \%$ & $14 \%$ & $7 \%$ & & \\
& 68 & 38 & 10 & 116 & \\
& $59 \%$ & $33 \%$ & $9 \%$ & & \\
\hline \hline
\end{tabular}

(30) You can ask these people/all around $M . /$ that know me, and they'll tell you I ain' never been no trouble since I been there. BL 135

(31) you know there was another party/between him, me an' him/ tha's the cause of our trouble. HS 597

The humanness of the NP head-more specifically, its having a human referent or not - has been shown by other researchers (e.g., Ball, 1996; Guy \& Bayley, 1995; Quirk, 1957; Romaine, 1982) to be of importance for the choice of relatives; except in the case of Romaine's Middle Scots, the systems of relativization they examined usually included who and which. Thus, Guy and Bayley (1995) found that humanness of the head noun usually favors who and disfavors the choice of that, but that zero is moderately favored for human antecedents in present-day standard American English. In the ExSlave Recordings, where who is not an option, however, human antecedent heads co-occur with zero with about the same frequency as that, whereas nonhuman antecedents mostly co-occur with zero, as demonstrated by Table 12 and illustrated in (32) and (33).

(32) That boy that killed my husban', I nursed him when he was a baby. HS 407

(33) But one little one what couldn' eat, they'd come to it. LS 70 
TABLE 13. Function of NP head in main clause

\begin{tabular}{lccccc}
\hline \hline & Zero & That & What & Total & $\%$ \\
\hline Direct object & 27 & 15 & 1 & 43 & $37 \%$ \\
Subject & $63 \%$ & $35 \%$ & $2 \%$ & & \\
& 7 & 14 & 6 & 27 & $23 \%$ \\
Subject complement & $26 \%$ & $52 \%$ & $22 \%$ & & \\
& 22 & 2 & 1 & 25 & $22 \%$ \\
Existential subject & $88 \%$ & $8 \%$ & $4 \%$ & & \\
Prepositional complement & 4 & 2 & 0 & 6 & $5 \%$ \\
No syntactic function & $67 \%$ & $33 \%$ & $0 \%$ & & $8 \%$ \\
& $44 \%$ & $33 \%$ & $22 \%$ & 9 & $8 \%$ \\
Total & 4 & 2 & 0 & 6 & $5 \%$ \\
& $67 \%$ & $33 \%$ & $0 \%$ & & \\
& 68 & 38 & 10 & 116 & \\
\hline \hline
\end{tabular}

Notice also that most of the relative complexes in our material have human referents $(63 \%)$. Moreover, seven out of the ten cases of what occur with human heads, and $84 \%$ of all cases of that have human referents, whereas only half of the zero constructions refer to humans. If we had only Table 12 to base our observations on, it would be easy to draw the conclusion that human reference of the head noun disfavors the choice of zero- only $47 \%$ of all instances have zero following human heads, compared with $79 \%$ when the heads are non-human. However, it is necessary to make a clear distinction between subject and object function of the relative.

Looking next at the syntactic function of the head noun in the matrix clause, we see from Table 13 that there is a variety of types here. Most NP heads function as direct objects in the matrix clause $(37 \%)$, followed by subjects with $23 \%$ and subject complements (predicate nominals) with $22 \%$. There is a sprinkling of prepositional complements $(8 \%)$ and subjects of existential constructions (5\%). ("No syntactic function" was registered for elliptic constructions, such as answers to questions.)

Two facts are noteworthy here. NP heads as subjects have only $26 \%$ zero relatives, but show a strong preference for that ( $52 \%$, compared with the sample average of $33 \%$ ), as in (34) and (35). On the other hand, subject complements have as many as $88 \%$ zero relatives, as in (36) and (37), but only $8 \%$ that.

(34) An' when they started a little school, why the people that were slaves, there couldn' many of them go to school.... FH 183

(35) All that I knowed they teach you is mind your master an' your mistress. HS 111 
TABLE 14. Function of relative marker in relative clause

\begin{tabular}{lccccc}
\hline & Zero & That & What & Total & $\%$ \\
\hline Subject & 23 & 28 & 6 & 57 & $49 \%$ \\
Direct object & $40 \%$ & $49 \%$ & $11 \%$ & & \\
& 38 & 8 & 4 & 50 & $43 \%$ \\
Prepositional complement & $76 \%$ & $16 \%$ & $8 \%$ & & \\
& 4 & 2 & 0 & 6 & $5 \%$ \\
Existential subject & $67 \%$ & $33 \%$ & $0 \%$ & & \\
& 3 & 0 & 0 & 3 & $3 \%$ \\
Total & $100 \%$ & $0 \%$ & $0 \%$ & & \\
& 68 & 38 & 10 & 116 & \\
\hline
\end{tabular}

(36) but the colored's the one $\varnothing$ wan' to throw me off the boat. CS 22

(37) The United State name me "Trigger Kid," but that's a name $\varnothing$ I've hated. CS 230

As we shall see, the function of the antecedent head in the matrix clause is shown by the variable rule analysis to be an independent factor in the selection of relative marker.

\section{Relative clause factors}

Let us turn next to the factor groups having to do with the relative clause itself. Looking first at the syntactic function of the relative marker (often called position in the literature), we see in Table 14 that there are four types present, with subject function accounting for $49 \%$ of the total, direct objects coming second with $43 \%$, and very low proportions of prepositional complements and existential subjects, $5 \%$ and $3 \%$, respectively. The fact that the proportion of object relatives is almost as high as that of subject relatives is interesting from a discourse point of view; it tallies well with the results of Fox (1987), who found similar proportions in a corpus of spoken contemporary American English and who argued for the importance of object relatives in the information flow in spoken discourse.

Notice that, although zero is the most frequent relative marker overall, this is not the case where the relative marker is the subject of the relative clause. In subject function that predominates with $49 \%$ of all tokens, and zero takes second place $(40 \%)$. This can be compared with object function, where zero is the absolute front runner, with $76 \%$ of all tokens, and that accounts for a mere $16 \%$ of all instances. The most frequent type of subject relative is exemplified by (38) and (39):

(38) An' I'm happy ... as somebody that's oh, got million. FH 29

(39) They treating me all now, that knows me, they treating me nice. AG 21 
Some examples of zero subjects are given in sentences (40) through (42):

(40) Garfield the first President $\varnothing$ ever was killed of the United States. CS 216

(41) Ain' but one white man $\varnothing$ try to objec' church and that was Mr. M. LS 610

(42) They had a, they had a preacher $\varnothing$ treated us fine. BL 181

These data and examples show the speakers in the Ex-Slave Recordings to be not unlike speakers of Appalachian English in their use of relative markers, as reported by Ball (1996), based on Hackenberg (1972). ${ }^{13}$ In the aggregated-data from the two lowest classes of speakers $(n=215)$, that is the leading marker, used in $61 \%$ of all subject relatives in restrictive relative clauses; zero comes second and is used in $35 \%$, and $w h$-pronouns are used in the remaining $4 \%$.

It is also interesting to compare the types of subject zero constructions used in EAAVE with those described by other writers on subject relatives in a large number of works dealing with social, regional, and historical varieties of English. ${ }^{14}$ Ball (1996) listed four types, in the following order, but without any quantitative information: existential constructions, constructions with have and get, it-clefts, and "other constructions" where the relative construction is not postverbal (as in Everybody $\varnothing$ lives in the mountains has an accent all to theirself, the quotation used as an epigraph to Wolfram and Christian's Appalachian Speech). All types except it-clefts are represented in our material - for examples of existentials and have-constructions, compare (41) and (42) - but we also found other types, where zero subjects followed subject complements $(n=7)$ and direct objects $(n=3)$, as in (43) and (44).

(43) Well, I've always have been, been $a$ woman $\varnothing$ would carry myself in a way that white an' colored both of them would care for me. CB 17

(44) Me an' Billy the Kid went an' got the man $\varnothing$ kill the President. CS 268

We are now in a position to relate our findings concerning the choice of relative marker in relation both to its syntactic function in the embedded clause and the humanness of the head noun. To begin with, consider the observation made by Schneider (1989:215) and taken up by Montgomery (1991:185), who said that "subject zero forms are much more likely to have human head nouns than nonhuman ones and object forms the reverse." Montgomery remarked that "[i]t is unclear why this is so." A cross-tabulation of our figures for humanness and syntactic function of relativizers gives the answer, as Table 15 demonstrates.

Table 15 shows that not only zero but also the other frequent relativizer (i.e., that) obey almost the same distributional and semantic constraints as far as humanness is concerned. Subject that has human referents in $96 \%$ $(27 / 28)$ of all cases - exactly the same proportion as that of zero relativizer with human referents, also $96 \%(22 / 23)$. Object that has $63 \%(5 / 8)$ nonhuman referents, which is somewhat less than object zero, with $76 \%(29 / 38)$, 
TABLE 15. Cross tabulation of humanness of referent and function of relative marker (subjects and direct objects only)

\begin{tabular}{lrrrr}
\hline \hline & Subject & \multicolumn{3}{c}{$\begin{array}{c}\text { Direct } \\
\text { Object }\end{array}$} \\
\hline Human & & & & \\
$\quad$ Zero & 22 & $(40 \%)$ & 9 & $(69 \%)$ \\
That & 27 & $(49 \%)$ & 3 & $(23 \%)$ \\
What & 6 & $(11 \%)$ & 1 & $(8 \%)$ \\
$\quad$ Subtotal & 55 & & 13 & \\
Non-human & & & & \\
$\quad$ Zero & 1 & $(50 \%)$ & 29 & $(78 \%)$ \\
$\quad$ That & 1 & $(50 \%)$ & 5 & $(14 \%)$ \\
What & 0 & $(0 \%)$ & 3 & $(8 \%)$ \\
$\quad$ Subtotal & 2 & & 37 & \\
Total & 57 & & 50 & \\
\hline \hline
\end{tabular}

TABLE 16. Subject of relative clause

\begin{tabular}{llllll}
\hline & Zero & That & What & Total & $\%$ \\
\hline Relative pronoun & 28 & 28 & 7 & 63 & $54 \%$ \\
& $44 \%$ & $44 \%$ & $11 \%$ & & \\
Personal pronoun & 39 & 9 & 2 & 50 & $43 \%$ \\
Definite NP & $78 \%$ & $18 \%$ & $4 \%$ & & \\
& 1 & 1 & 1 & 3 & $3 \%$ \\
Total & $33 \%$ & $33 \%$ & $33 \%$ & & \\
& 68 & 38 & 10 & 116 & \\
\hline \hline
\end{tabular}

but the tendency seems clear. The answer to Montgomery's question is simply that subjects in general tend to be human. In our sample $96 \%(55 / 57)$ of all subject relatives are human, but only $26 \%(13 / 50)$ of the objects are. These proportions naturally vary depending on the text type studied, but our EAAVE sample is similar to other investigations of spoken discourse. See Macaulay (1991:64f.), Fox (1987), and especially Fox and Thompson (1990), who showed that, in a corpus of spoken contemporary American English, object relatives with non-human subject heads outnumbered other relatives by a factor of 5 to 1 .

If we take a look at the subjects of relative clauses, we see from Table 16 that in most cases $(54 \%)$ ) the relative markers had subject function, but that when they did not subjects tended to be personal pronouns $(43 \%)$. When the subject was a personal pronoun, the relative marker was most often a zero form $(78 \%)$ ) (see Table 17). This tallies well with other studies (e.g., Tottie, 
TABLE 17. Category membership of subject in relative clauses with non-subject relative marker

\begin{tabular}{llllll}
\hline & Zero & That & What & Total & $\%$ \\
\hline Personal pronoun & 39 & 9 & 2 & 50 & $94 \%$ \\
& $78 \%$ & $18 \%$ & $4 \%$ & & \\
Definite NP & 1 & 1 & 1 & 3 & $6 \%$ \\
& $33 \%$ & $33 \%$ & $33 \%$ & & \\
Total & 40 & 10 & 3 & 53 & \\
& $75 \%$ & $19 \%$ & $6 \%$ & & \\
\hline \hline
\end{tabular}

1995), which showed a strong correlation between personal pronoun subjects and (non-subject) zero relatives in written British and American present-day English, but no independent effect could be found in the variable analysis of this material.

Stranded prepositions, of which there were a total of five in the main sample, occurred with either zero (three times) or that (twice), as in (45) and (46). In the adverbial sample there were also examples with what and where; compare (9) through (12).

(45) None, none of the rest of them that I know of is living. FH 241

(46) That's the name $\varnothing I$ go in now. CS 110

Resumptive pronouns in the relative clause occurred five times, once with what and four times with that. It is perhaps worth noting that there were no instances of zero relativizer followed by a resumptive pronoun. Compare (2), (47), and (48).

(47) they jus' have these white, these B.s that they kill our white, our, our boys, my husban' and his brother, was poor white boys. HS 500

(48) I say "I never ask N.'s for a nickel what they didn' give it to me. .." BL 48

\section{The relative marker as a sociolinguistic variable}

Several earlier researchers have paid attention to the function of the relative marker as a sociolinguistic or sociohistorical variable: notably, Romaine (1982) and Macaulay (1991) for Scottish English, Cheshire (1982) for Reading English, and Adamson (1992) for American English. Adamson, who carried out a VARBRUL analysis of his material of 2,240 relative constructions from 300 hours of spoken American English, found that zero relatives had a probability of .40 in upper-class speech, compared with .68 in working-class speech. Adamson did not differentiate between subject and non-subject function of zero relatives, and neither did we when we decided to investigate the possibility of the variable being sensitive to gender. ${ }^{15}$ 
TABLE 18. Relative marker usage of male and female speakers

\begin{tabular}{llllcc}
\hline \hline & Zero & That & What & Total & $\%$ \\
\hline Male & 49 & 21 & 5 & 75 & $65 \%$ \\
& $65 \%$ & $28 \%$ & $7 \%$ & & \\
Female & 19 & 17 & 5 & 41 & $35 \%$ \\
& $46 \%$ & $41 \%$ & $12 \%$ & & \\
Total & 68 & 38 & 10 & 116 & \\
& $59 \%$ & $33 \%$ & $9 \%$ & & \\
\hline
\end{tabular}

Table 18 shows the distribution of relative markers over male and female speakers. We see that the men had a higher proportion of zeroes than the women: $65 \%$ compared with $46 \%$. Gender also turned out to be an independent factor in the variable rule analysis. The smallness of the present sample, as well as our lack of knowledge of the social dynamics of the communities where the ex-slaves had lived, makes it necessary to be cautious in interpreting these quantitative data. The issue seems worth pursuing on the basis of a larger sample, however, in order to find out if zero relativization is a gendersensitive variable showing the classic pattern of women adhering more closely to the prestige norm than men.

\section{VARIABLE RULE ANALYSIS}

A variable rule analysis of the main sample was carried out using GolDVARB (Rand \& Sankoff, 1990). The following factor groups were tested: for the matrix clause, the category, premodification, humanness, and syntactic function of the antecedent head noun as well as adjacency of the head and the relative marker; for the embedded clause, the syntactic function of the relative marker in the relative clause and the category membership of the subject of the relative clause; and the sociolinguistic factor, speaker gender. The program was run in its binomial version, with zero as the application value. The results are shown in Table 19.

Of the factor groups tested, three matrix clause factor groups were selected by the program as making independent contributions to the choice of relative marker in non-adverbial relative clauses: the syntactic function of the antecedent head in the matrix clause, the humanness of the referent of the head, and the adjacency of head and relative marker. In the first group, the greatest contribution to the choice of zero relative marker was made by the function as subject complement, where the probability of zero was .841 , followed by the function as subject in an existential sentence, where the probability was $\mathbf{8 2 2}$. Subject function and prepositional complement function disfavored zero relativizer with probabilities of .207 and .192, respectively, 
TABLE 19. Factors contributing to the choice of zero relativizer (using GOLDVARB)

\begin{tabular}{lc}
\hline Matrix clause factors & $p$ \\
\hline Function of head & \\
Subject complement & 0.841 \\
Subject in existential sentence & 0.822 \\
In constructions with ellipsis & 0.557 \\
Direct object & 0.483 \\
Subject & 0.207 \\
Prepositional complement & 0.192 \\
Humanness of Head & \\
Human & 0.343 \\
Non-human & 0.751 \\
Adjacency of Head and Relative Marker & 0.578 \\
Adjacent & 0.122 \\
Not adjacent & \\
Sociolinguistic factor & \\
Sex of Speaker & 0.601 \\
Male & 0.322 \\
Female & \\
Input 0.628 Log likelihood $=-54.348$ Significance $=0.026$ \\
\hline
\end{tabular}

whereas direct object function and syntactically indeterminate function in ellipted sentences were intermediate with probabilities of .483 and .557 , respectively. Human heads tended to disfavor zero with a probability of .343 , whereas non-human heads favored zero markers with a .751 probability. Non-adjacency of the antecedent head and relative marker strongly disfavored zero with a probability of .122 , whereas adjacent head-marker constructions showed a probability of .578 for zero relative.

Speaker gender showed a neat differentiation between male and female speakers, with a .601 probability of zero relativization for men and .322 for women. But keep in mind the cautionary remarks made earlier.

We were somewhat surprised that the factor groups premodification and subject of the relative clause were not selected as significant, as earlier studies had indicated that premodification and pronominal subjects influenced the choice of relativizer. Because both of the groups contained large numbers of irrelevant examples (non-premodifiable heads in the premodification category and sentences where the relative markers were themselves subjects in the subject category), we created two new subsamples, one consisting only of premodifiable examples $(n=94)$ and another where all sentences with relative markers as subjects were eliminated $(n=53)$. However, this did not cause the factors premodification of the antecedent head or personal pronoun as subject of the relative clause to be selected as having an independent contribution to the selection of zero relative. In the case of premodification, this is probably attributable to the fact that only certain types of premodifying elements, such as the ones singled out by Olofsson (1981) as special modifi- 
ers with certain semantic properties, tend to select zero relatives. In the case of pronominal subjects, the answer is more difficult to find. However, it seems likely that the selection of pronominal subjects as making independent contributions to the choice of zero relatives in Tottie (1995) could have to do with two characteristics of that study: it was based on a sample consisting only of written English, and the sample consisted only of relativizers in nonsubject function.

\section{CONCLUDING REMARKS}

Our investigation has shown that the EAAVE used by the speakers of the ExSlave Recordings had a system of relativization which in many ways resembles other vernaculars, such as the Middle Scots examined by Romaine (1982), the Scottish English of Ayrshire documented by Macaulay (1991), Appalachian English as described by Hackenberg (1972), Wolfram and Christian (1976), and Montgomery and Chapman (1992), and the Dorset dialect investigated by Van den Eynden (1993). Some important common factors are the lack or low incidence of who and which and the correspondingly high incidence of that, the frequency of zero relatives in subject position, and the occasional use of what as a relative marker. The high frequency of subject zeroes in particular underlines the character of EAAVE as an English vernacular; its occurrence must be related to the limited exposure to literacy of our informants. As Romaine pointed out (1982:78), contra Bever and Langendoen (1971), sentences like The girl knew the man became sick are ambiguous only in writing and present no problem in the spoken language, where "tonic placement would probably disambiguate most doubtful cases." Romaine went on to say that "there is no reason to believe [subject relative deletion] is any less frequent now than it was centuries ago." We know that subject zeroes were more frequent than object zeroes in Old and Middle English; the gradual reversal of this situation in late Middle English and Early Modern English was probably due to increased literacy (see Dekeyser, 1984, 1986). Construing the high incidence of subject zeroes as a sign of a creole origin of EAAVE thus seems uncalled for. See also Aitchison (1992:310), who suggested, in a study of Tok Pisin (which has a well-developed system of relative markers), that there may even be "an intrinsic need for creoles in particular ... to acquire markers, so as to make constructions transparent," and that a "need to mark relative clauses overtly may be part of a similar tendency towards transparency."

The similarity between adverbial relative constructions in standard varieties of English and the EAAVE samples is also a striking feature underlining the position of EAAVE on a continuum of English dialects or, perhaps more appropriately, a fuzzy dialect map. The question whether zero relativization functions as a fundamentally class-based prestige factor affecting men and women differently needs to be examined further.

We have been able to underpin with additional evidence the conclusions of Schneider (1989) and Montgomery (1991): the EAAVE relative system, as 
it appears in the Ex-Slave Recordings, does not support the creole hypothesis advanced by Dillard (1972) and others. If there were deeper vernaculars of creole origin (contemporary or older), a possibility suggested by Rickford (1991), we have no evidence of their existence.

As is usual, we must end with a call for further research, both concerning relativization and AAVE. Although relativization in English is a well-tilled field, earlier studies are often difficult to compare because of the selection of data and the varying selection of factors investigated. As pointed out by Ball (1996), we need more studies of relative markers (including adverbial relatives), based on well-defined linguistic varieties and text types, and a careful selection of factors to investigate.

We also need more work on relativization in contemporary AAVE, where there is a surprising lack of knowledge concerning this variable. New research is likely to shed valuable light on many unsolved questions, for several reasons. Relativization is what might be called a covert variable, an unobtrusive part of the linguistic system which does not draw attention to itself like many of the much-studied variables pertaining to the verb phrase and negation; it is therefore unlikely to be subject to conscious alteration on the part of speakers, and yet it is extremely accessible to study because of its frequency. Moreover, since there is already a substantial body of knowledge concerning the universals of relativization and their relation to other linguistic universals (see Keenan \& Comrie, 1977), a better knowledge of the system of relativization could lead to deeper insights into the system of AAVE as a whole.

\section{NOTES}

1. See, for example, monographs on British English dialects, such as Van den Eynden (1993), or sociolinguistic works, such as Cheshire (1982) or Macaulay (1991).

2. Montgomery (1991) based his comparison on Schneider (1982), a journal article based on Schneider's (1981) German-language dissertation. Our references will be to Schneider (1989), the English translation of Schneider (1981). This makes no difference as regards the data referred to.

3. Schneider carefully speaks of subject and non-subject zeroes, but Montgomery renders this as subject and object relatives - clearly a mistake, as adverbial relatives are nowhere mentioned.

4. See Rickford (1991:194): "In the statistical sense of having been selected by random sampling, [the Ex-Slave Recordings] are clearly NOT representative, but probably no less so than in most sociolinguistic surveys (which make a virtue of having vaguely defined 'judgment' samples)."

5. We regard the tapes as primary data and the transcripts as "analogues," following Bailey et al. (1991).

6. In one case, we thought we heard an instance of who'd rather than zero plus would (Harriet Smith 491, Bailey et al., 1991:93), but we decided to defer to the editors.

7. There is thus a slight difference in numbers from Montgomery, who had 158 examples in all. This could be due to the fact that we looked especially for adverbial relatives.

8. We found fewer non-restrictive relatives than Montgomery (1991), which can partly be explained by the fuzzy line between restrictives and non-restrictives, but also to different criteria applied.

9. We found relative constructions in only ten of the samples; none occurred in the speech of "Joe McDonald and Woman."

10. According to a National Public Radio broadcast on September 19, 1995, about a quarter of all cowboys were Black.

11. For time expressions, they list the day on which she arrived, the day which she arrived on, the day that she arrived on, the day $\varnothing$ she arrived on, the day when she arrived, the day $\varnothing$ she arrived, the day that she arrived in addition to the bare (non-relative) when she arrived. 
12. Others (e.g., Romaine 1982) have used the categories animate and inanimate; we follow Macaulay (1991) in using the labels human and non-human, as we do not think it makes a difference here. There were two animate heads (horses) among the non-humans.

13. Unfortunately, Wolfram and Christian (1976) give no quantitative survey of the use of relative markers in their Appalachian English material. They exemplified the existence of subject zero constructions and reported that they "found very few instances" of what as a relative marker (1976:121). Montgomery and Chapman (1992) found a high incidence of subject zeroes in their diachronic study of existential constructions in Appalachian English.

14. See Mustanoja (1960), Bever and Langendoen $(1971,1972)$, and especially Romaine (1982) for examples and discussion of the disappearance of subject zeroes from the standard language. 15. When carrying out our research, we were not aware of Montgomery and Chapman's (1992) study, which shows that in Appalachian English the use of zero subjects in existential constructions has gone down more markedly in the speech of women than in that of men.

\section{REFERENCES}

Adamson, H. D. (1992). Social and processing constraints on relative clauses. American Speech 67:123-133.

Aitchison, Jean. (1992). Relative clauses in Tok Pisin: Is there a natural pathway? In Marinel Gerritsen \& Dieter Stein (Eds.), Internal and external factors in syntactic change. Berlin: Mouton de Gruyter. 295-316.

Bever, T., \& Langendoen, T. (1971). A dynamic model of evolution of language. Linguistic Inquiry 2:433-465.

(1972). The interaction of speech perception and grammatical structure in the evolution of language. In R. P. Stockwell \& R. K. S. Macaulay (Eds.), Linguistic change and generative theory. Bloomington: Indiana University Press. 32-95.

Bailey, Guy, Maynor, Natalie, \& Cukor-Avila, Patricia. (1991). The emergence of Black English. Amsterdam and Philadelphia: John Benjamins.

Ball, Catherine. (1994). Relative pronouns in it-clefts: The last seven centuries. Language Variation and Change 6:179-200.

Ball, Catherine. (1996). A diachronic study of relative markers in spoken and written English. Language Variation and Change 8:227-258.

Cheshire, Jenny. (1982). Variation in an English dialect. Cambridge: Cambridge University Press.

Dekeyser, Xavier. (1984). Relativizers in Early Modern English. A dynamic quantitative study. In Jacek Fisiak (Ed.), Historical syntax. Berlin: Mouton de Gruyter. 61-87.

Dekeyser, Xavier. (1986). English contact clauses revisited: A diachronic approach. Folia Linguistica Historica 7:107-120.

Dillard, J. L. (1972). Black English: Its history and usage in the United States. New York: Vintage Books.

Fischer, Olga. (1992). Syntax. In Norman Blake (Ed.), The Cambridge history of the English language, vol. 2. Cambridge: Cambridge University Press. 207-408.

Fox, Barbara A., \& Thompson, Sandra A. (1990). A discourse explanation of the grammar of relative clauses in English conversation. Language 66:297-316.

Fox, Barbara. (1987). The noun phrase accessibility hierarchy revisited. Language 63:856-870.

Guy, Gregory R., \& Bayley, Robert. (1995). On the choice of relative pronouns in English. American Speech 70:148-162.

Hackenberg, Robert. (1972). Appalachian English: a sociolinguistic study. Doctoral dissertation, Georgetown University.

Jespersen, Otto. (1927). A modern English grammar on historical principles. Part III. Heidelberg: Carl Winter.

Keenan, Edward, \& Comrie, Bernard. (1977). Noun phrase accessibility and universal grammar. Linguistic Inquiry 8:63-99.

Labov, William, \& Cohen, Paul. (1973). Some suggestions for teaching standard English to speakers of nonstandard urban dialects. In Johanna S. DeStefano (Ed.), Language, society and education: A profile of Black English. Worthington, OH: Charles A. Jones. 218-237.

Light, Richard. (1969). Syntactic structures in a corpus of non-standard English. Doctoral dissertation, Georgetown University. 
Macaulay, Ronald. (1991). Locating dialect in discourse: The language of honest men and bonnie lassies in Ayr. Oxford: Oxford University Press.

Martin, Stefan, \& Wolfram, Walt. (in press). The sentence in African American Vernacular English. In John Rickford, Salikoko Mufwene, Guy Bailey, \& John Baugh (Eds.), The structure of African American Vernacular English. London: Routledge.

McKay, June Rumery. (1969). A partial analysis of a variety of Nonstandard Negro English. Doctoral dissertation, University of California, Berkeley.

Montgomery, Michael. (1991). The linguistic value of the Ex-Slave Recordings. In Guy Bailey et al. (Eds.), The emergence of Black English. Amsterdam: John Benjamins. 173-189.

Montgomery, Michael, \& Chapman, Curtis. (1992). The pace of change in Appalachian English. In Matti Rissanen, Ossi Ihalainen, Terttu Nevalainen, \& Irma Taavitsainen (Eds.), History of Englishes. New methods and interpretations in historical linguistics. Berlin: Mouton de Gruyter. 624-639.

Mufwene, Salikoko. (1986). Restrictive relativization in Gullah. Journal of Pidgin and Creole Languages 1:1-31.

Mustanoja, Tauno. (1960). A Middle English syntax. Part 1: Parts of speech. Mémoires de la Société Néophilologique de Helsinki 23.

Myhill, John. (1995). The use of features of present-day AAVE in the Ex-Slave Recordings. American Speech 70:115-147.

Olofsson, Arne. (1981). Relative junctions in written American English. Gothenburg Studies in English 50.

Orton, Harold, Sanderson, Stewart, \& Widdowson, John (Eds.). (1978). The linguistic.atlas of England. London: Croom Helm.

Quirk, Randolph, Greenbaum, Sidney, Leech, Geoffrey, \& Svartvik, Jan. (1985). A comprehensive grainmar of the English language. London: Longman.

Quirk, Randolph. (1957). Relative clauses in educated spoken English. English Studies 38:97-109.

Rand, David, \& Sankoff, David. (1990). Goldvarb. Version 2. A variable rule application for the Macintosh. Centre de recherches mathématiques, Université de Montréal.

Rawick, George P. (Ed.). (1972). The American slave: A composite autobiography. Contributions in Afro-American and African studies. Westport, CT: Greenwood Press.

Rickford, John R. (1991). Representativeness and reliability of the Ex-Slave narrative materials, with special reference to Wallace Quarterman's recording and transcript. In Bailey et al. (Eds.), The emergence of Black English. Amsterdam: John Benjamins. 192-212.

Romaine, Suzanne. (1982). Socio-historical linguistics. Its status and methodology. Cambridge: Cambridge University Press.

Rydén, Mats. (1966). Relative constructions in early sixteenth century English. With special reference to Sir Thomas Elyot. Uppsala: Acta Universitatis Upsaliensis.

Schneider, Edgar W. (1981). Morphologische und syntaktische Variabeln im amerikanischen Early Black English. Bamberger Beiträge zur englischen Sprachwissenschaft 10. Frankfurt: Peter Lang.

Schneider, Edgar W. (1982). On the history of Black English in the USA: Some new evidence. English World-Wide 3:18-46.

Schneider, Edgar W. (1989). American Earlier Black English. Tuscaloosa: University of Alabama Press.

Smith, Riley B. (1969). Interrelatedness of certain deviant grammatical structures in Negro nonstandard dialects. Journal of English Linguistics 3:82-88.

Tottie, Gunnel. (1995). The man $\varnothing$ I love: An analysis of factors favouring zero relatives in written British and American English. In Gunnel Melchers \& Beatrice Warren (Eds.), Studies in Anglistics. Stockholm Studies in English. Stockholm: Almqvist and Wiksell. 201-215.

Van den Eynden, Nadine. (1993). Syntactic variation and unconscious linguistic change. A study of adjectival relative clauses in the dialect of Dorset. Frankfurt: Peter Lang.

Wolfram, Walt, \& Christian, Donna. (1976). Appalachian speech. Arlington, VA: Center for Applied Linguistics. 